\title{
AUTORIDADE PEDAGÓGICA OU AUTORITARISMO NA EDUCAÇÃO PARA A INFÂNCIA? REFLEXÕES EM HANNAH ARENDT E A TEORIA CRÍTICA
}

\author{
AUTORIDAD PEDAGOGICA O AUTORITARISMO EN LA EDUCACIÓN PARA LA \\ INFANCIA? REFLEXIONES EN HANNAH ARENDT Y LA TEORÍA CRÍTICA
}

\author{
PEDAGOGICAL AUTHORITY OR AUTHORITARIANISM IN EDUCATION FOR \\ CHILDREN? REFLECTIONS IN HANNAH ARENDT AND THE CRITICAL THEORY
}

\author{
Marta Regina Furlan de OLIVEIRA ${ }^{1}$
}

\begin{abstract}
RESUMO: O objetivo principal do texto é refletir acerca da autoridade pedagógica ou autoritarismo nos espaços formativos voltados para a educação da infância, tecendo um diálogo entre Hannah Arendt e a Teoria Crítica. Este texto se justifica pela necessidade de análise dos possíveis equívocos que são decorrentes das teorias modernas da pedagogia e da educação, que influenciam as práticas educativas voltadas ao trabalho com crianças entre 0 e 5 anos. A metodologia de trabalho está no estudo bibliográfico com a leitura principal da obra Entre $o$ passado e o futuro de Hannah Arendt (2013) dialogando com a Teoria Crítica a partir da obra Educação e Emancipação em Theodor Adorno (1985). Como resultado, as inquietações apresentadas pela autora e dialogadas com Adorno e Horkheimer, suscitam-nos a repensar a escola e, desse modo, buscar novos horizontes pedagógicos em favor de um trabalho formativo emancipatório da infância.
\end{abstract}

PALAVRAS-CHAVE: Autoridade. Professores. Hannah Arendt. Teoria crítica. Educação infantil.

RESUMEN: El objetivo principal del texto es reflexionar acerca de la autoridad pedagógica o autoritarismo en los espacios formativos dirigidos a la educación de la infancia, tejiendo un diálogo entre Hannah Arendt y la Teoría Crítica. Este texto se justifica por la necesidad de análisis de los posibles equívocos que se derivan de las teorías modernas de la pedagogía y de la educación, que influencian las prácticas educativas dirigidas al trabajo con niños entre 0 y 5 años. La metodología de trabajo está en el estudio bibliográfico con la lectura principal de la obra Entre el pasado y el futuro de Hannah Arendt (2013) dialogando con la Teoría Crítica a partir de la obra Educación y Emancipación en Theodor Adorno (1985). Como resultado, las inquietudes presentadas por la autora y dialogadas con Adorno y Horkheimer, nos suscita a repensar la escuela y, de ese modo, buscar nuevos horizontes pedagógicos en favor de un trabajo formativo emancipatorio de la infancia.

PALABRAS CLAVE: Autoridad. Profesores. Hannah Arendt. Teoría crítica. Educación Infantil.

\footnotetext{
${ }^{1}$ Universidade Estadual de Londrina (UEL), Londrina - PR - Brasil. Pós-Doc. em Educação. Programa de PósGraduação em Educação da Universidade Estadual de Londrina. ORCID: <http://orcid.org/0000-0003-21462557>. E-mail: marta.furlan@yahoo.com.br
} 
ABSTRACT: The main objective of the text is to reflect on the pedagogical authority or authoritarianism in the formative spaces directed to the education of the childhood, weaving a dialogue between Hannah Arendt and the Critical Theory. This text is justified by the need to analyze the possible misunderstandings that are due to the modern theories of pedagogy and education that influence educational practices aimed at working with children between 0 and 5 years old. The methodology of work is in the bibliographic study with the main reading of the work Between the past and the future of Hannah Arendt (2013) dialoguing with the Critical Theory from the work Education and Emancipation in Theodor Adorno (1985). As a result, the anxieties presented by the author and dialogued with Adorno and Horkheimer, lead us to rethink the school and, thus, to seek new pedagogical horizons in favor of emancipatory formative work of childhood.

KEYWORDS: Authority. Teachers. Hannah Arendt. Critical theory. Child education.

\section{Introdução}

A forma dominante de pensar mantém os espíritos na mais profunda cegueira [...] não há liberdade na sociedade dissociada do verdadeiro pensamento esclarecido [...]. (Adorno e Horkheimer)

Ao refletir acerca dos espaços formativos contemporâneos voltados ao trabalho educativo com crianças entre 0 e 5 anos, tem-se a preocupação acerca de como vem sendo constituída a autoridade pedagógica que atua nesse campo de ensino. A inquietação é notória pelo próprio caminho trilhado do conceito de autoridade pedagógica que ora é traduzido pelo autoritarismo pedagógico ou superioridade do adulto com práticas educativas cerceadoras do conhecimento; ora está voltado ao processo de neutralização e silenciamento formativo da razão, com ações sem intencionalidade e distantes do que deveria ser o propósito educacional para a primeira infância.

Desse modo, o objetivo do texto é analisar a autoridade pedagógica e autoritarismo na educação para a infância, tecendo um diálogo entre Hannah Arendt e Teoria Crítica, a fim de pensarmos em redirecionamentos para o trabalho docente infantil. Para tanto, questiona-se: Como tem sido constituído o processo de autoridade pedagógica ou autoritarismo nos espaços formativos voltados à infância na contemporaneidade? Quais redirecionamentos se fazem urgentes para o trabalho com as crianças em favor uma educação emancipatória?

A autoridade tem sido reincidentemente interrogada em diferentes instâncias no cenário contemporâneo. Nas instituições tradicionais como a família e a escola, há um discurso premente em torno de uma suposta crise. Pais e professores reclamam de uma precarização da autoridade e responsabilizam o outro por esse processo de desautorização. Há, ainda, equívocos decorrentes da própria teoria moderna da pedagogia e educação, que influenciam 
significativamente as práticas educativas com crianças. A crise da autoridade, seja pela família, ou pela escola, acaba desse modo, fragilizando a formação humana e o próprio processo de aprendizagem e conhecimento na vida de crianças e adolescentes.

Diante disso, utilizaremos os apontamentos de Hannah Arendt na obra Entre o passado e o futuro (2013) e a Teoria Crítica a partir da obra Educação e Emancipação em Theodor Adorno (1985); uma vez que contribuem de maneira efetiva para o trabalho pedagógico no campo da educação desde a mais tenra idade. Esse estudo é atual e urgente, podendo ser remetido não somente no processo formativo de atuação pedagógica, mas, principalmente, desde a formação inicial do profissional pedagógico, com vistas a uma nova perspectiva educacional, voltada para os princípios efetivos de garantia do conhecimento, da crítica, da reflexão e da autonomia dos sujeitos envolvidos.

Os conceitos elencados por Arendt, Adorno e Horkheimer serão refletidos nesse texto, a fim de compreendermos o processo de constituição da autoridade/autoritarismo no campo educativo. Nesta análise, serão considerados os conceitos fundamentais de crise da educação e de autoridade pedagógica abordados por Arendt, bem como as contribuições de Adorno, a partir do movimento de luta contra a barbárie.

Para que a discussão seja melhor compreendida, é fundamental o entendimento do contexto social vigente, sendo hoje marcado pela Indústria Cultural e pelo processo semiformativo. A frieza e a barbárie, decorrentes do suposto progresso civilizatório, se refletem na educação, além de provocar uma mudança no quadro de valores da sociedade e cultura. Podemos afirmar a ilustre frase de Arendt (2013): "a história da cultura é um vasto cemitério de obras cadentes". Nesse sentido, estar sujeito à dominação, ou ser capaz de conquistar a sua liberdade intelectual decorrerá do conhecimento adquirido pelo cidadão e sua atuação social. O conhecimento, aliado à posse de modernos aparatos tecnológicos, pode tanto trazer o desenvolvimento como transformar o homem em objeto da dominação, fazendo-o refém da indústria cultural.

Em se tratando do termo indústria cultural, foi utilizado pela primeira vez, por Horkheimer e Adorno, no ensaio, Indústria Cultural: iluminismo como sedução das massas, publicado em 1947, cuja expressão é apontada por Adorno (1977) como uma cultura que serve aos interesses do capitalismo, que a partir da revolução tecnológica redefine as condições de produção e reprodução da cultura.

Neste contexto, assistimos ao declínio da razão e da autoridade pedagógica face ao mundo cada vez mais avançado tecnologicamente. Pode-se ousar afirmar que a autoridade foi recusada pelos adultos, sendo que estes, se recusaram a assumir a responsabilidade pelo mundo 
ao qual trouxeram as crianças. A própria autoridade estabelecida no mundo moderno, sejam elas as autoridades paternas e pedagógicas estão sendo sucumbidas pelos ditames semiformativos à luz da Indústria Cultural e da neutralização da razão. O que seria de responsabilidade para o homem moderno sobre a vida da criança, se perdeu, quando este se infantilizou frente a adaptação e ao conformismo humano. O homem moderno, seduzido pelos fetiches da técnica e da mercadoria, está cada vez mais se eximindo de tal empreitada de autoridade (ARENDT, 2013).

Diante disso, o desafio epistemológico está em renovar olhares, perspectivas e compreensões no sentido de aspirarmos novos direcionamentos pedagógicos voltados para uma formação humana mais digna e autônoma de nossas crianças.

\section{Sobre o conceito de autoridade na educação}

O ser humano que não é mais chamado pelo nome se torna um indivíduo de uma humanidade perdida (Yves Cattin).

Hannah Arendt (2013), no texto Que é Autoridade? aponta para a crise da autoridade como movimento típico do mundo moderno, relacionado historicamente à perda da tradição, ou seja, à crise nos conceitos universais: autoridade e liberdade, que para o mundo grego, eram sinônimos de responsabilidade e cuidado para com os valores históricos e humanos. Neste sentido, as contribuições de Hannah Arendt (1906-1975) são fundamentais para a compreensão do papel educacional e pedagógico no contexto atual, pois seus estudos trazem implicações significativas no campo da educação, dando uma atenção especial ao ensino e ao papel da autoridade pedagógica docente no trabalho educativo desde a educação infantil.

As reflexões arendtianas emergiram ao longo dos anos 40 e 50 tendo dois temas fundamentais desse período pós-guerra, a saber: o totalitarismo e a banalização do mal, uma vez que os regimes totalitários de esquerda ou de direita tiveram como pressuposto a aniquilação das classes sociais, a atomização das pessoas, e a uniformidade e homogeneidade sociais.

Em seus escritos, a autora chama a atenção para a crise das autoridades tradicionais, concordando que a crise constante da autoridade acompanha o desenvolvimento do mundo moderno em nosso século, afetando as relações entre a autoridade familiar e a pedagógica. Afirma que o fim da tradição que aconteceu com o advento da modernidade não é especulação nem é um juízo de valor, mas um fato politicamente palpável. 
Com a modernidade, as comunidades políticas deixaram de ser sustentadas pelos valores e costumes tradicionais ${ }^{2}$. A tradição, segundo a autora, perdeu o poder de organizar e dar um sentido para a vida política e comunitária. Em se tratando dos valores tradicionais, que antes reuniam os valores máximos da humanidade, estes perderam a validade objetiva e foram desmascarados como parciais e ideológicos. Afirma, ainda, que o sintoma mais significativo da crise, "pela sua profundeza e seriedade" é ter se espalhado no campo familiar, com a educação dos filhos, e no contexto educativo e institucional (ARENDT, 2013 p. 128).

A autoridade que perdemos no mundo moderno não é esta "autoridade em geral", mas antes uma forma bem específica, que fora válida em todo o mundo ocidental durante longo período de tempo. Proponho-me, portanto, a reconsiderar o que a autoridade foi historicamente e as fontes de sua força e significação.

Ao buscar a tradição filosófica, a autora afirma que a razão, na medida em que se tornou critério para o exercício do poder, perdeu a sua dimensão contemplativa, e a sua autonomia, relacionada ao conhecimento e à compreensão do real, transformou-se em instrumento, em meio para submetê-lo e controla-lo (FERRAZ, 1978). Com a perda da tradição não se perde o passado, mas se perde "o fio que nos guiou com segurança pelos vastos domínios do passado" (ARENDT, 2013 p. 130). A tradição, a despeito da errônea identificação com a religião não é o passado, mas a memória, que resguarda a profundidade da existência humana. Sem memória, sem experiência, não há consistência no desenvolvimento dos processos educacionais. Ficamos ameaçados pelo esquecimento e, mergulhados no calor irracional e acrítico da multidão (ARENDT, 2013).

Essa realidade é vivida na contemporaneidade em que a sociedade se permite iludir por mecanismos sedutores da indústria cultural, conduzindo, nos sujeitos que dele participam, o desenvolvimento da personalidade voltada a extraordinária superficialidade do pensar. Essa realidade atual não está distante do que Arendt afirma ser a superficialidade do pensamento, quando ao se referir ao Julgamento de Eichmann em Jerusalém tenta explicar a "banalidade do mal" com a seguinte afirmativa. Por mais monstruosos que fossem os atos, o agente não era nem monstruoso nem demoníaco; a única característica específica que se podia detectar em seu passado, bem como em seu comportamento durante o julgamento e o inquérito policial que o precedeu, é que não se tratava de estupidez, mas de uma curiosa e bastante autentica incapacidade de pensar (ARENDT, 2013).

${ }^{2} \mathrm{O}$ fim da tradição com o surgimento da modernidade é um tema recorrente em Arendt. Está em seu livro Entre o passado e o futuro, principalmente no prefácio intitulado "A quebra entre o passado e o futuro" e no capitulo "A tradição e a época moderna” (ARENDT, 2013). 
Arendt, então, estabelece as características fundamentais do conceito de autoridade, advertindo que a questão proposta no título deveria ser outra: não se trata do que é autoridade, mas o que foi a autoridade. Afirma que a autoridade desapareceu do mundo moderno em função de uma crise constante. Entretanto, mesmo diante dessa crise, a autora formula uma definição do conceito de autoridade que pode ser compreendido "a-historicamente", ou seja, apesar de tal conceito ter sido pensado sobre uma base de experiências históricas determinadas, ele possui um conteúdo, uma natureza e uma função definidos, passíveis de serem compreendidos na atualidade mesmo apesar do suposto fenômeno de desaparecimento da autoridade do mundo moderno (ARENDT, 2013).

Em suas reflexões, esclarece que nem autoridade é compatível com tirania, nem tradição é exatamente o mesmo que passado. Nesse sentido, a crise da autoridade foi originariamente política, com os movimentos políticos e as formas de governo totalitárias surgidas durante a primeira metade do século XX. Entretanto, essa crise se espalha também em áreas pré-políticas, tais como a criação dos filhos e a educação "onde a autoridade no sentido mais lato sempre fora aceita como uma necessidade natural" (ARENDT, 2013, p. 128). A ruína "mais ou menos geral e mais ou menos dramática de todas as autoridades tradicionais" foi o grande substrato possibilitador da ocorrência generalizada de governos totalitários a partir do início deste século.

Além de dedicar-se à reflexão sobre a crise da autoridade, Arendt procura compreender como se estabelece uma autoridade legítima, e se essa legitimidade não reside na violência e/ou na força, ela também não reside na persuasão, pois persuadir implica que a relação se estabeleça numa esfera de igualdade, haja vista que a eficiência da ordem se dá pelo melhor argumento. Acredita, desse modo, que uma relação mediada pela violência angaria obediência, mas uma obediência por medo e não por respeito não pode ser considerada como um projeto de autoridade e de educação e, sim de autoritarismo. Sobre esse ponto, podemos afirmar que, muitas vezes, cria-se uma cultura escolar do medo e da punição, inibindo em crianças e alunos em geral a verdadeira consciência do que seja autoridade.

A autoridade, por outro lado, é incompatível com a persuasão, a qual pressupõe igualdade e opera mediante um processo de argumentação. Onde se utilizam argumentos, a autoridade é colocada como suspenso. A relação autoritária entre o que manda e o que obedece não assenta nem na razão comum nem no poder do que manda; o que eles possuem em comum é a própria hierarquia, cujo direito e legitimidade ambos reconhecem e no qual ambos têm seu lugar estável predeterminado (ARENDT, 2013, p. 129).

Nesse sentido, o conceito de autoridade diferencia-se de outras relações entre os indivíduos que implica obediência, como a força e a violência. De fato, busca as origens do 
conceito e sua utilização com as contribuições dos romanos, na tarefa de desvendar os equívocos de compreensão desse conceito. Afirma a autora, que se a autoridade exigir obediência, então ela perdeu seu sentido de autoridade. "Contudo a autoridade exclui a utilização de meios externos de coerção; onde a força é usada, a autoridade em si fracassou" (ARENDT, 2013, p. 129).

Arendt no ensaio A crise na educação relaciona a crise da autoridade e a crise da educação americana no final dos anos 60 com a crise geral do mundo moderno, demonstrando sua presentificação e relevância. Crise esta que é entendida pela autora como tendo correlação direta com a crise da república norte-americana ${ }^{3}$. Hannah Arendt aponta a crise da autoridade como pano de fundo para a transformação dos movimentos políticos totalitários do século XX. Neste contexto, a experiência totalitária produziu uma situação absolutamente nova, sem condições de inteligibilidade a partir dos padrões tradicionais de compreensão. A ideia de governo total era inerente à eliminação da política e o terror, o medo, o silêncio e a solidão eram os sustentáculos dessa tentativa de governo (ARENDT, 2013).

Nesse prisma, para compreender a atual crise da educação e dos conceitos de autoridade/autoritarismo, é necessário que nossos horizontes pedagógicos sejam emancipados, no intuito de refletir a atual crise como um fenômeno social e político e, não restritamente local, fragmentado. Ainda, o descompromisso com a educação desde a infância é fato notório na contemporaneidade, uma vez que, no mundo da mercadoria e da produção, os conceitos estão sendo alterados e negligenciados em favor do consumo e da padronização do pensamento. Desse modo, os adultos (sejam eles pais e professores) estão se negando a assumir a tal responsabilidade de ensinar e orientar as crianças e jovens acerca do mundo e da responsabilidade que as palavras e ações humanas assumem.

Segundo Arendt, a função da escola é ensinar às crianças como o mundo é, e não instruílas na 'arte de viver'. Sua argumentação é a favor da autoridade na sala de aula e sua visão educativa é assumidamente conservadora. Isso não quer dizer que ela defenda um professor autoritário, tampouco é favorável à escola como um agente da manutenção da ordem estabelecida; ao contrário, a autora acredita que a criança desde seu início deve ser apresentada ao mundo e estimulada a mudá-lo pelo processo de educação e emancipação em que Adorno, tão claramente, defende.

${ }^{3}$ É interessante notar que Arendt escreve suas reflexões sobre a crise na educação americana no contexto histórico pós Segunda Guerra Mundial, em que Theodor Adorno também procura compreender a educação após Auschwitz, isto é, após o horror. 


\section{Autoridade Pedagógica ou Autoritarismo: Algumas provocações}

A educação é o ponto em que decidimos se amamos o mundo o bastante para assumirmos a responsabilidade por ele e, com tal gesto, salvá-lo da ruína que seria inevitável não fosse a renovação e a vinda dos novos e dos jovens (Hannah Arendt)

Compreender esse processo da autoridade pedagógica ou autoritarismo na educação de crianças entre 0 e 5 anos é o nosso desafio na presença-ausência da autoridade docente e suas implicações no processo de ensinar e aprender. O diálogo entre Adorno e Arendt torna-se fundamental nesta análise como parâmetro crítico de compreensão efetiva deste fenômeno na educação.

$\mathrm{Na}$ sociedade atual é fato que as teorias modernas trazem uma repercussão maior da ausência de autoridade pedagógica nas escolas infantis; considerando que a modernidade não significa necessariamente tempos melhores, ao contrário, é necessário que haja compreensão crítica das informações que estão em toda a parte. No caso, se consideramos que conhecer o mundo não significa simplesmente estar nele e ter acesso a informações sobre ele; ao contrário, estar no mundo é ir além de um "abrir portas" que é mecânico e indiferente. Para isso, o papel do professor é, muito mais, o de mediador entre o mundo e as crianças e os jovens. Assim, seu papel de mediador lhe exige uma responsabilidade dupla, ou seja, como professor torna-se responsável pela educação de suas crianças, mas também faz parte de seu papel assumir, diante delas, a responsabilidade pelo mundo por meio do processo de ensino e aprendizagem (ALMEIDA, 2011).

Quando não há a responsabilidade docente em ensinar as crianças os caminhos que elas desconhecem, mas que precisam conhecer, pode-se pensar em uma possível ausência de autoridade para com a educação efetiva de crianças, conforme afirma Arendt (2013). Essa crise ou ausência de autoridade pode ser decorrente dos próprios cursos de formação pedagógica que, em sua estrutura mercadológica e aligeirada, fragilizam a formação deste profissional que atua com a educação da infância. Há uma desvalorização social, política, econômica e pedagógica de professores de educação infantil, sendo confundido com uma visão romantizada de "mãe, tia" ou alguém que somente ame as crianças. A ação deste profissional acaba resultando em ações de assistência e cuidado de crianças de 0 a 5 anos. Quando não, a responsabilidade docente é traduzida por práticas de escolarização infantil com a prontidão para a alfabetização.

Para Arendt (2013) a crise é de natureza política. Assegura que a crise da autoridade está relacionada à crise da tradição, isto porque está implícito na natureza da educação tanto a 
autoridade quanto a tradição. Ela afirma que se a educação é eminentemente política, então, a autoridade pedagógica também está em crise.

É obvio que na vida pública e política, autoridade ou não representa mais nada, pois a violência e o terror exercidos pelos países totalitários evidentemente nada têm a ver com autoridade - ou, no máximo, desempenha um papel altamente contestado (ARENDT, 2013, p. 239-240).

Essa autoridade pedagógica é expressão de um contexto em que os conceitos de autoridade isentam o adulto de sua responsabilidade em educar crianças, sendo esse fato, característica presente no contexto da família e escola contemporâneas. Uma questão preocupante são as alterações de conceitos de educação e os próprios modismos pedagógicos de valorização subjetiva do ser humano, que retiram da escola infantil, a sua função social e política de garantir os conhecimentos historicamente acumulados, bem como os valores morais.

Ora, não é de se estranhar que a própria Arendt levante três ideias básicas que poderiam justificar essa "catástrofe" política e educacional que é a crise da autoridade. Segundo a autora, a primeira é que se criaram uma sociologia de valorização da infância e do ser criança que lhe dá o direito de assumir uma autonomia desde o início, enquanto que, os adultos são desincumbidos de sua responsabilidade na educação e orientação pedagógica para o exercício do pensar e da consciência verdadeira, conforma afirma Adorno (1995). Nesta lógica de pensamento, muitos profissionais envolvidos na educação infantil acreditam que o papel dos adultos deve, então, consistir em limitar-se a assistir a esse processo de declínio da autoridade com o fortalecimento do grupo das crianças que detém a autoridade e que permitirá dizer a cada criança o que ela deve e não deve fazer. Nesse sentido, a pretensão de libertar as crianças da autoridade dos adultos como se fossem uma "minoria oprimida" (ARENDT, 2013, p. 240) é, praticamente, isentar os adultos de decisões que somente a eles cabem a respeito do processo educativo.

\footnotetext{
Negando sua participação (ativa ou não) no mundo, recusam seu papel como coautores em sua constituição. Fazendo livre uso de uma expressão idiomática, poderíamos dizer que se recusam a "assinar embaixo". Essa conduta de desresponsabilização pelo mundo ou até rejeição a ele impossibilita, em princípio, a tarefa educativa (ALMEIDA, 2011, p. 43)
}

Em Arendt (2013) a autoridade de um grupo, mesmo que seja de crianças, acaba sendo mais impactante e tirano do que a mais severa autoridade de um indivíduo isolado. O segundo pressuposto básico está relacionado ao ensino, em que este é influenciado pelas contribuições modernas da psicologia e das doutrinas pragmáticas que acabaram alterando os conceitos relacionados à pedagogia e à educação. A perspectiva pragmática da educação gera fragilidades 
no que se refere a autoridade pedagógica e ao ensino crítico, propriamente dito. Há um esvaziamento dos conceitos críticos em detrimento de concepções infundadas de aprendizagem e de conhecimento escolar. Essa realidade afeta os espaços formativos voltados a primeira infância, já que o próprio pragmatismo está novamente na "moda", em que se afirma e reafirma à luz de conceitos superficiais das teorias modernas na tentativa de responder questões do ensino e da aprendizagem.

A crise da educação abordada por Arendt coincide com o diagnóstico de Adorno quando questiona o papel da escola e da educação. Nesse sentido, Theodor Adorno em sua obra "Educação e Emancipação" (1995) também analisa os impactos da semiformação no campo educativo e na formação e atuação do profissional da educação desde a primeira infância, sendo que esse conceito está próximo ao que Arendt apresenta. Nesse sentido, o autor estabelece o seguinte questionamento: Educação, para quê? A partir desta questão provocadora, pode-se pensar sobre como tem sido desenvolvido o trabalho educativo docente e qual é o estado atual de formação cultural desses profissionais com vistas à emancipação humana. Inseparáveis do contexto social, os processos formativos tornam-se lócus desta crise na educação, em virtude do pensamento unificador e homogêneo, em que há a percepção nítida da crise de autoridade pedagógica, quando os profissionais estão mergulhados no processo de semiformação.

Arendt refere-se à condição de formação de professores, quando trata da crise com o ensino, afirmando que as influências psicológicas e pragmáticas atingem o campo da formação docente, em que muitos profissionais, mergulhados no processo de semiformação, acabam sabendo apenas "um pouco mais" do que suas crianças. As consequências são inevitáveis: os alunos são abandonados aos seus próprios meios, como também ao professor é retirada a "fonte mais legítima da sua autoridade enquanto professor" (ARENDT, 2005, p. 231).

\footnotetext{
Isso quer dizer, por sua vez, que não apenas os estudantes são efetivamente abandonados a seus próprios recursos, mas também que a fonte mais legítima da autoridade do professor, como a pessoa que, seja dada a isso a forma que se queira, sabe mais e pode fazer mais que nós mesmos, não é a mais eficaz. Dessa forma, o professor não-autoritário, que gostaria de se abster de todos os métodos de compulsão por ser capaz de confiar apenas em sua própria autoridade, não pode mais existir (ARENDT, 2013, p. 231).
}

Adorno comunga a ideia de Arendt ao afirmar acerca do deslumbramento pelo processo tecnológico a que se deixam levar os profissionais da educação que, de certa forma, provoca nos mesmos a degeneração do pensamento reflexivo, ameaçando o conteúdo crítico e emancipado em razão da determinação social e da própria padronização e embrutecimento do pensamento. Há a ilusão de que o futuro educacional das crianças esteja relacionado a uma 
organização técnica atualizada com as melhores tecnologias para satisfazer tal exigência educativa. Em Arendt (2013) essa ação é perigosa e frágil, uma vez que se a educação deixa de se preocupara com as heranças do passado (historicamente acumuladas), os mais novos também não poderão cuidar do mundo do futuro. "Sem tradição [...] parece não haver nenhuma continuidade consciente no tempo, e portanto, humanamente falando, nem passado nem futuro, mas tão somente a sempiterna mudança do mundo e do ciclo biológico das criaturas que nele vivem" (ARENDT, 2013, p. 31).

Esse fato acaba aprofundando a crise da autoridade pedagógica nos espaços formativos, quando se voltam às práticas ativistas e sem reflexão. Algumas consequências podem ser evidenciadas: dominação progressiva; rigorosa objetividade científica; eliminação do sujeito por meio de sua auto conservação; perda da tradição; extraordinário entusiasmo pedagógico por tudo aquilo que é novo; brilho da falsa racionalidade vazia pela ilusão da razão subjetiva que acaba por tornar falsidade sua própria essência, a objetividade da verdade.

A adaptação não ultrapassa a sociedade, que se mantém cegamente restrita. A conformação às relações debate-se com as fronteiras do poder [...]. Desse modo, a adaptação reinstala-se e o próprio espírito converte-se em fetiche, em superioridade do meio organizado universal sobre todo fim racional e no brilho da falsa racionalidade vazia. Ergue-se uma redoma de cristal que, por desconhecer-se julga liberdade. E essa consciência falsa amalgama-se por si mesma à igualdade falsa e soberba atividade do espírito (PUCCI et al., 2010 p. 12)

A educação, nesse sentido, é impactada pelos fetiches e utopias sociais e políticas, pela adoção dos modismos pedagógicos e sistemas de padronização a que se deixam levar por essas ilusões aplicadas à educação formativa. Adorno utiliza o exemplo mais prático desse fenômeno que é o da "propaganda educacional", objetivando levar à escola a maior quantidade de pessoas, sem refletir sobre questões fundamentais e no próprio papel social da escola: o que é e para que é a educação (ADORNO, 1995, p. 139).

Arendt, então, afirma que:

O extraordinário entusiasmo por tudo aquilo que é novo, visível em quase todos os aspectos da vida quotidiana americana, bem assim como a correspondente confiança numa 'perfectibilidade indefinida' - aquilo que Tocqueville considerou ser o credo do 'homem vulgar não instruído' e que, enquanto tal, precede em quase uma centena de anos um desenvolvimento semelhante nos outros países ocidentais (ARENDT, 2013, p. 224)

Nesse processo, a autoridade pedagógica, em específico, assim como toda a atividade do homem moderno, transformou-se em mera técnica ou aplicação de conhecimentos produzidos pelas ciências da educação, atendendo à necessidade social de aumento da 
eficiência, da demanda de qualificação profissional e dos padrões de consumo e do pensamento. Na verdade, em sua crítica à neutralidade aparente da ciência, Arendt questionava a euforia em torno do progressivo tecnicismo em um mundo no qual as palavras perderam seu poder e no qual a humanidade poderia ser escravizada pelo seu próprio conhecimento prático (Know-how), indefeso em razão do divórcio entre o conhecimento técnico e matematizante e o pensamento que convém ao raciocínio discursivo e, por extensão, à origem da ação política. Mera atividade repetidora, incapaz de traduzir-se em experiências narráveis do conhecimento.

O cenário descrito acima nos leva ao terceiro pressuposto anunciado por Arendt devido ao uso acrítico pela escola da teoria moderna de aprendizagem, em que pelo processo de incorporação dos modismos pedagógicos, os espaços formativos abriram as janelas para as ideologias de ensino e aprendizagem. Respaldados por conceitos arendtianos podemos inferir que nesta perspectiva de aprendizagem "só é possível conhecer e compreender aquilo que nos mesmos fizermos, e sua aplicação à educação é tão primária quanto óbvia", ou seja, apresentamos a nova forma de ensinar e aprender que "consiste em substituir, na medida do possível, o aprendizado pelo fazer" que nada mais é do que a tão anunciada - pedagogia ativa ou pedagogia do fazer.

Essa lógica de aprendizagem é muito usual nos espaços educativos voltados à infância, quando o ativismo supera o conteúdo e a reflexão. Pode-se dizer que há uma busca sem limites por "fazeres" e "saberes" em que, principalmente os professores ficam deslumbrados pelo mundo do receituário educativo. Essa prática é tão naturalizada no campo da educação, que se transformou no grande lema educacional, que se traduz na redução do saber ao fazer. Essa proposta ativista acaba sendo malconduzida nos espaços formativos, principalmente, quando confundida com a manipulação motora dos objetos e materiais ou produção de atividades manuais, por exemplo. Há também a intenção de criar, com as reformas educativas, um novo modelo de escola, agora a escola lúdica, do espetáculo, pelo processo do brincar, da ludicidade em que acaba sendo banalizado o conhecimento como algo que esteja próximo à diversão.

O pensamento, portanto, é convertido em mero conhecimento prático ou ativista. Podemos, assim, dizer que os fatos recentes na educação de crianças traduzem efetivamente o divórcio entre o conhecimento técnico e o conhecimento emancipador. Há nesse processo, um endeusamento pelos modelos, pelas técnicas, pelas atividades em si; sem se prender à busca pelo conhecimento dos conceitos e pela razão crítica. Há, ainda, os que são iludidos pelas falácias de suposta autoridade que na prática traduzem efetivamente a superioridade do adulto sobre a criança com ações inibidoras, de humilhação e autoritarismo. 
Ao contrário desta visão educativa, desde a infância a criança precisa ser instigada ao conhecimento e à busca crítica do pensar pelo processo do ensino e aprendizagem. Os professores envolvidos devem se assumir a responsabilidade de educar e de instigar o conhecimento emancipado. Arendt aponta que há uma aceitação servil e acrítica nas mais modernas teorias pedagógicas como se fossem capazes de superar as fragilidades do ensino e resolver todos os problemas enfrentados nos espaços formativos. Outro ponto problemático é que na busca pela valorização das diferenças, a escola acaba cometendo um grande equívoco: ao igualar ou apagar tanto quanto possível a diferença entre velhos e novos, entre dotados e não dotados, enfim, entre professores e crianças, o processo de nivelamento educativo articula-se com a perda da autoridade pedagógica.

\section{Considerações finais}

Este texto desenvolveu a reflexão acerca do conceito de autoridade pedagógica e autoritarismo na educação para a infância, tendo como premissa o diálogo entre Hannah Arendt e Teoria Crítica acerca do trabalho pedagógico no campo educacional. Para isso, analisou as implicações das teorias modernas, especificamente, no campo da educação infantil, em que pela "inovação" de concepções, acarretou equívocos pedagógicos para o trabalho com as crianças. A principal implicação desse processo é o próprio esvaziamento da capacidade de pensar, do olhar crítico; em substituição ao trabalho do saber pelo processo do fazer.

Além disso, a crise de autoridade também é percebida nos espaços de formação inicial em que por um processo deficitário e aligeirado do conhecimento, muitos profissionais pedagógicos que atuam diretamente com a criança acabam distorcendo seus propósitos educativos, em função de um mundo da utilidade, do fazer, da superficialidade e do esvaziamento dos sentidos e, caminham para o autoritarismo do saber.

As contribuições de Hannah Arendt, nesse sentido, marcam a discussão atual, em que pelos modismos e equívocos pedagógicos deixamo-nos levar por práticas ora disciplinadoras e autoritárias, ora espontâneas e não diretivas. Diante disso, a autora afirma que, enquanto escola e educação, "estamos de fato em confronto com um simultâneo retrocesso tanto da liberdade como da autoridade no mundo moderno" (ARENDT, 2013, p. 138). A busca pela "liberdade educacional" provoca consequências significativas no campo da autoridade pedagógica, fragilizando as relações entre autoridade e ensino. Ora, na reafirmação da liberdade, esvaziouse a autoridade enquanto responsável pelo conhecimento e pela formação humana. Esse fato é percebido quando profissionais e adultos "não sabem o que fazer com as crianças", 
submetendo-as a ações precoces de punição infantil e outros tipos de autoritarismo e manipulação humana.

Ainda que, neste percurso, algumas dificuldades tenham sido suscitadas no campo educacional, acreditamos que o investimento na formação crítica inicial e continuada de professores, bem como no próprio repensar do processo educativo com ações emancipatórias do conhecimento, da responsabilidade e autoridade pedagógica que se faz assumir, podem ser caminhos de ressignificação do trabalho pedagógico com as crianças desde a mais tenra idade.

\section{REFERÊNCIAS}

ADORNO, T. W. Educação e Emancipação. Trad. Wolfgang L. Maar. Rio de Janeiro: Paz e Terra, 1995.

ALMEIDA, V. S. Educação em Hannah Arendt: entre o mundo deserto e o amor ao mundo. São Paulo: Cortez, 2011.

ARENDT, H. Entre o passado e o futuro. Tradução Mauro W. Barbosa de Almeida. $1^{\text {a }}$ reimpressão da $7^{\mathrm{a}}$ ed. São Paulo: Perspectiva, 2013.

CATTIN, Y. O ser humano: Transgressor de Fronteiras. Revista Concilium, 280, 1999/2. Petrópolis: Vozes. p. 27.

FERRAZ, T. Política e ciência política. Brasília. Editora UnB, 1978 (Coleção Textos de Aula).

HORKHEIMER, M. Eclipse da Razão. Tradução de Sebastião Uchoa Leite. São Paulo: Centauro, 2002.

PUCCI, B.; et al. (org). Teoria Crítica e Inconformismo: novas perspectivas da pesquisa. Campinas, São Paulo: Autores Associados, 2010 - Coleção Educação Contemporânea.

\section{Como referenciar este artigo}

OLIVEIRA, Marta Regina Furlan de. Autoridade Pedagógica ou Autoritarismo na Educação para a Infância? Reflexões em Hannah Arendt e a Teoria Crítica. Revista Ibero-Americana de Estudos em Educação, Araraquara, v. 14, n. 2, p. 456-469, abr./jun., 2019. E-ISSN: 19825587. DOI: $10.21723 /$ riaee.v14i2.11505

Submetido em: 26/06/2018

Aprovado em: 11/11/2018 